Jurnal Keperawatan Silampari

Volume 3, Nomor 1, Desember 2019

e-ISSN :2581-1975

p-ISSN :2597-7482

DOI: https://doi.org/10.31539/jks.v3i1.515

\title{
KECEPATAN PELAPORAN BERBASIS SISTEM INFORMASI DAN PEMERIKSAAN MANUAL SESUAI STANDAR PELAYANAN KEMENTERIAN KESEHATAN
}

\author{
Sa'adah Mujahidah $^{1}$, Melyana Nurul Widyawati ${ }^{2}$ \\ Program Pascasarjana Magister Terapan Kebidanan, Poltekkes Kemenkes Semarang ${ }^{1,2}$ \\ saadah.mujahidah16@gmail.com ${ }^{1}$
}

\begin{abstract}
ABSTRAK
Tujuan penelitian ini untuk melihat dan mengetahui perbedaan kecepatan pelaporan berbasis sistem informasi dengan pemeriksaan manual sesuai standar prosedur pelayanan kemenkes. Penelitian ini merupakan jenis penelitian kuantitatif dengan rancangan penelitian quasy eksperimental menggunakan desain posttest only with control group design. Hasil penelitian menunjukkan terdapat perbedaan waktu pelaporan antara pelaporan berbasis sistem informasi dengan pelaporan manual pada ibu postpartum dengan pemeriksaan sesuai standar kemenkes dengan p-value 0,000 $(<0,005)$. Simpulan, sistem informasi berbasis web mempercepat waktu pelaporan hasil pelayanan kesehatan ibu postpartum dibandingkan dengan pemeriksaan manual sesuai standar pelayanan kemenkes.
\end{abstract}

Kata Kunci : Nifas, Kecepatan, Sistem Informasi, Waktu Pelaporan

\section{ABSTRACT}

The purpose of this study was to see and find out the differences in the speed of information-based reporting systems with manual inspection according to the Ministry of Health service standard procedures. This research is a quantitative research with quasy experimental research design using posttest only with control group design. The results showed that there was a difference in reporting time between reporting based on information systems with manual reporting on postpartum mothers with examinations according to the Ministry of Health standards with a p-value of 0,000 (<0.005). In conclusion, web-based information systems accelerate the reporting time of postpartum maternal health services compared to manual checks according to the Ministry of Health's service standards.

Keywords: Postpartum, Speed, Information Systems, Time Reporting 


\section{PENDAHULUAN}

Angka Kematian Ibu (AKI) merupakan salah satu indikator penting dari derajat kesehatan masyarakat. Berdasarkan data Survei Penduduk Antar Sensus (SUPAS) tahun 2015, AKI di Indonesia tahun 2015 sebesar 305 per 100.000 kelahiran hidup (KH) angka ini menurun dari tahun 2012 dimana AKI di Indonesia sebesar 359 per 100.000 kelahiran hidup (Kementrian Kesehatan Republik Indonesia, 2016). Berdasarkan laporan KIA Kabupaten/Kota di Provinsi Jawa Tengah data AKI mengalami penurunan dari 111,16 per 100.000 kelahiran hidup pada tahun 2015 menjadi 109,65 per 100.000 kelahiran hidup pada tahun 2016 (Dinas Kesehatan Provinsi Jawa Tengah, 2016). Padatahun 2016, dari 32 kasus kematian ibu, kondisi ibu pada saat meninggal paling banyak terjadi pada masa nifas sebesar 71,87\% (Dinas Kesehatan Kota Semarang, 2016).

Sulitnya akses untuk mendapat pelayanan kesehatan sering dialami oleh ibu nifas. Akses layanan umumnya lebih tinggi di daerah perkotaan. Hambatan pemanfaatan layanan meliputi jarak ke fasilitas kesehatan dan biaya layanan. Pada kenyataannya hampir separuh ibu di perkotaan tidak memperoleh akses ke fasilitas kesehatan meski memiliki akses geografis yang lebih baik, hal ini menunjukkan bahwa perlunya alternatif lain mengenai akses pelayanan kesehatan (Renfrew et al., 2014, Shiferaw et al., 2016). Padahal setiap wanita memiliki hak untuk mengakses layanan kesehatan yang berkualitas. Sasaran Sustainable Development Goal (SDG)yaitu menurunkan angka AKI di dunia menjadi kurang dari 70 kematian ibu per 100.000 kelahiran hidup pada tahun 2030, tanpa adanya satu negara yang memiliki rasio AKI lebih besar dari 140 kematian ibu per 100000 Kelahiran Hidup (Koblinsky et al., 2016).

Adanya keterlambatan dalam pelaporan memicu semakin memburuknya keadaan pasien karena keterlambatan dalam penegakan diagnosa akan berakibat terjadi keterlambatan dalam penanganan suatu penyakit (Cheng et al., 2013, Kristensen et al., 2017, Minghella et al., 2010, Trayner and Taylor, 2017). Keterlambatan dalam melakukan pelaporan akan berdampak pada terlambatnya pengambilan keputusan klinis yang harus ditegakkan (Fajriya, 2017). Kecepatan pelaporan hasil pemeriksaan akan berdampak pada perubahan pengambilan keputusan yang lebih cepat (Warren et al., 2015).

Beberapa penelitian menunjukkan bahwa solusi penggunaan sistem informasi seperti pesan teks (SMS), pesan video, panggilan suara dan konektivitas internet dapat meningkatkan pelayanan kesehatan dalam proses pengiriman data dan hasil kesehatan, kepatuhan pengobatan, kepatuhan pemantauan pasien (Shiferaw et al., 2016). Data yang didapatkan dengan pemanfaatan sistem informasi dapat dilihat oleh tenaga kesehatan kapan saja dan dimana saja yang akan mendukung tenaga kesehatan dalam melakukan pengambilan keputusan klinis (Miah et al., 2017). Dengan adanya sistem pendukung keputusan klinis akan sangat membantu tenaga kesehatan dalam mengambil keputusan terkait dengan kesehatan pasien karena data yang diperoleh lebih lengkap dan akurat (Bakibinga et al., 2017, Graham et al., 2016).

Tujuan penelitian ini adalah untuk melihat dan mengetahui perbedaan kecepatan pelaporan berbasis sistem informasi dengan pemeriksaan manual sesuai standar prosedur pelayanan kemenkes. 


\section{METODE PENELITIAN}

\section{Jenis dan Rancangan Penelitian}

Penelitian ini merupakan jenis penelitian quasy eksperimental dengan desain posttest only with control group design. Dalam penelitian dibagi menjadi 2 kelompok yaitu kelompok intervensi dan kelompok kontrol. Kelompok intervensi adalah ibu nifas yang mendapatkan pelayanan masa nifas dengan penerapan intervensi sistem informasi pada ibu nifas dan untuk kelompok kontrol adalah ibu nifas yang mendapatkan pelayanan masa nifas sesuai standar pelayanan dari Kementrian Kesehatan pada ibu postpartum.

Penelitian ini dilakukan di wilayah Puskesmas. Teknik sampling yang digunakan adalah non probability sampling dengan consecutive sampling, dengan jumlah sampel yaitu 40 responden. Kelompok intervensi $(n=20)$ menggunakan sistem informasi, sedangkan kelompok kontrol $(\mathrm{n}=20)$ dengan menggunakan standar pelayanan dari Kemenkes. Intervensi dilakukan selama 42 hari dalam tiga tahap pemeriksaan, kemudian dilakukan post test untuk melakukan evaluasi kecepatanpelaporan sistem informasi dengan menggunakan stopwatch dan kuesioner.

\section{Diagram Kerja Sistem Informasi}

Diagram kerja sistem informasi yang dibangun ditunjukkan dengan gambar 1. dibawah ini

INPUT

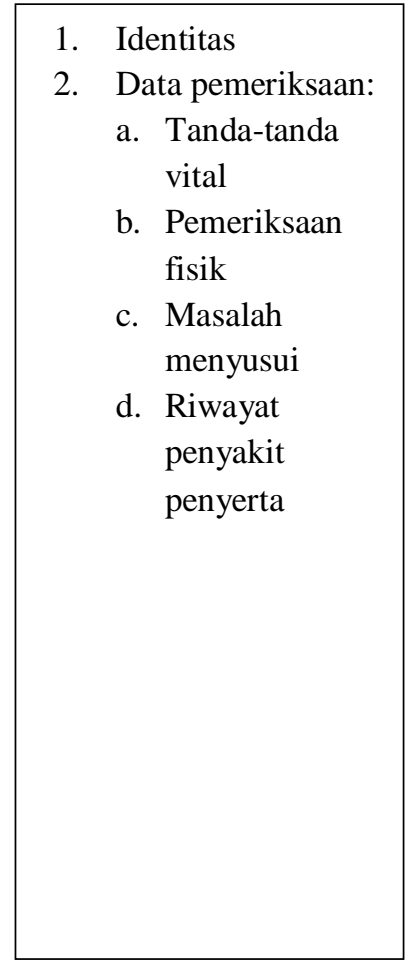

PROSES

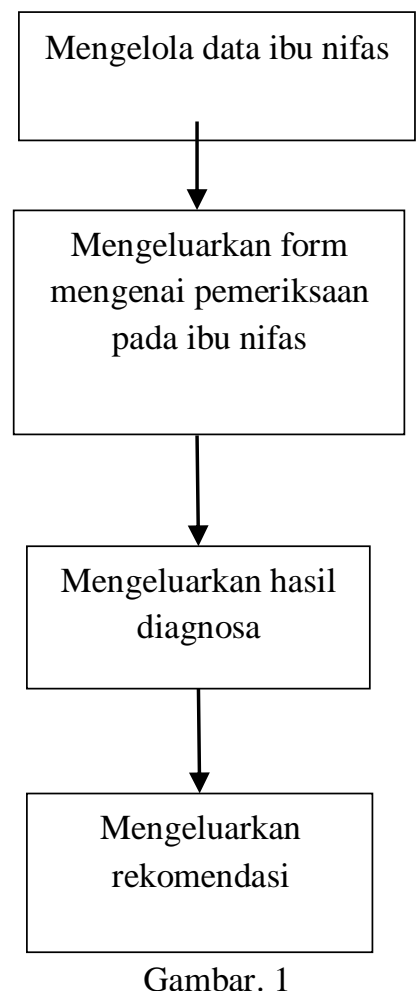

Diagram kerja sistem informasi
OUTPUT
Laporan hasil

pemeriksaan 


\section{Kerangka Kerja}

Sistem informasi yang dirancang adalah sistem informasi berbasis web. Akses informasi yang terdapat dalam sistem informasi dilakukan secara online sehingga membutuhkan koneksi internet. Bidan menginput data serta hasil pemeriksaan ibu nifas, kemudian diproses oleh sistem informasi yang menghasilkan laporan hasil pemeriksaan. Informasi diagnosa nifas yang terdapat dalam sistem informasi dilakukan validasi dengan 2 orang pakar, dalam hal ini yaitu bidan. Perhitungan uji validitas sistem informasi dilakukan dengan cara menggunakan pengukuran nilai data benar dibagi nilai data keseluruhan dikalikan $100 \%$.

\section{HASIL PENELITIAN}

\section{Gambaran Sistem Pelaporan Berbasis Web}

Sistem pelaporan yang dibangun terjaga keamananya dengan adanya menu log in dimana tidak semua orang dapat melakukan akses pada sistem informasi ini. Menu log in dapat dilihat pada gambar 2:

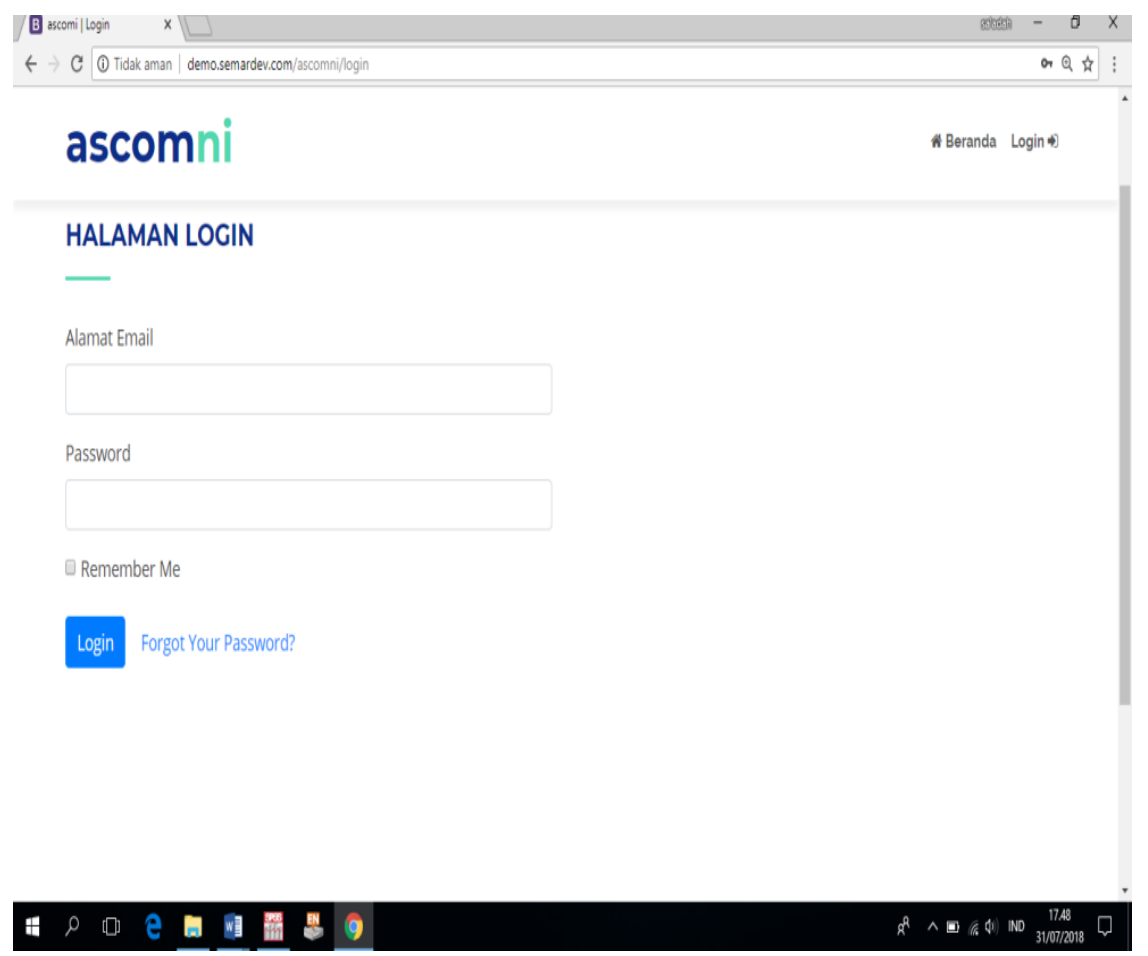

Gambar. 2

Menu $\log$ in

Setelah melakukan log in maka pengguna (usser) dapat melakukan pengisian identitas pasien secara lengkap yang dapat dilihat pada gambar 3: 


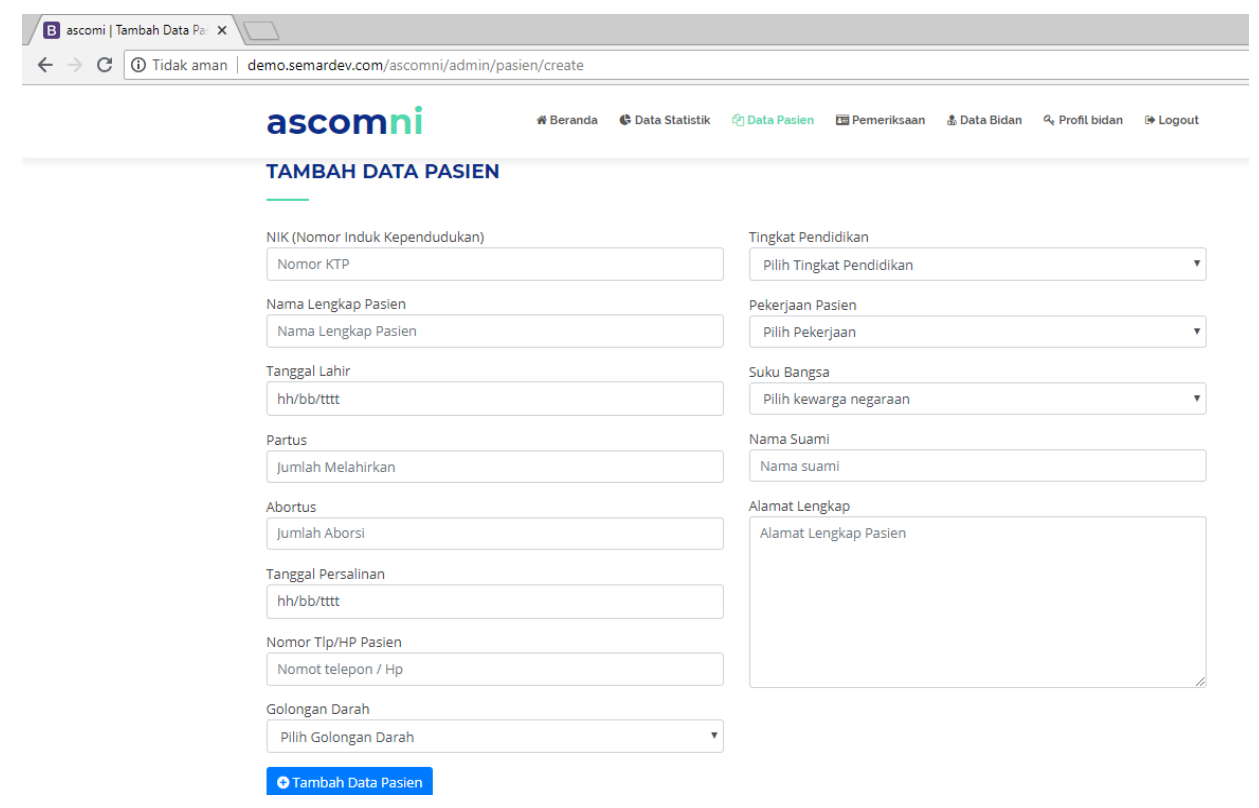

Gambar. 3

Data Identitas Pasien

Setelah melakukan input data pasien maka petugas kesehatan dapat memasukkan hasil pemeriksaan yang telah dilakukan dan sistem secara otomatis akan membuat laporan hasil pemeriksaan yang terlihat pada gambar 4:

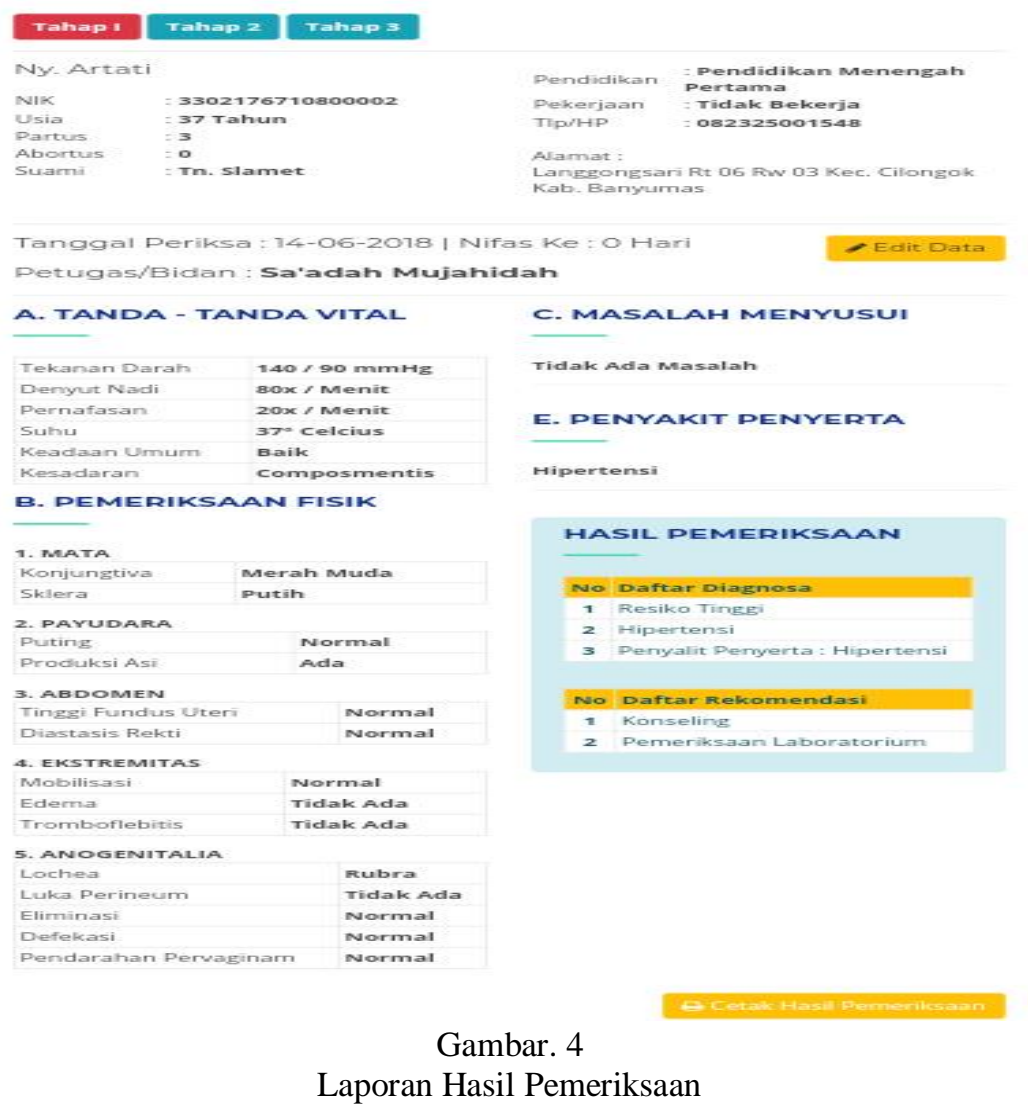


Sistem akan secara otomatis membuat hasil laporan pemeriksaan yang akan memudahkan bagi tenaga kesehatan untuk melakukan koordinasi dan mempercepat waktu pelaporan sehingga jika terdapat permasalahan yang terjadi pada pasien akan segera dapat tertanggulangi dengan baik.

\section{Kecepatan Waktu Pelaporan}

Sistem informasi pelayanan nifas dibuat secara online untuk dapat membuat laporan hasil pemeriksaan nifas secara otomatis. Data distribusi frekuensi waktu kecepatan sistem pelaporan pemeriksaan fisik nifas berbasis sistem informasi dapat dilihat dalam tabel 1 di bawah ini:

Tabel. 1

Distribusi Frekuensi Kecepatan Sistem Pelaporan

\begin{tabular}{|c|c|c|c|c|c|}
\hline \multirow{3}{*}{ No } & \multirow{3}{*}{ Waktu } & \multicolumn{4}{|c|}{ Kelompok } \\
\hline & & \multicolumn{2}{|c|}{$\mathrm{X}_{1}$ (Sistem Informasi) } & \multicolumn{2}{|c|}{$\begin{array}{c}\mathrm{X}_{2} \text { (Manual Standar } \\
\text { Kemenkes) }\end{array}$} \\
\hline & & Frekuensi & $\%$ & Frekuensi & $\%$ \\
\hline \multicolumn{6}{|c|}{ Kecepatan sistem pelaporan pemeriksaan fisik nifas } \\
\hline 1 & 09.30 menit & 1 & 5 & - & - \\
\hline 2 & 06.10 menit & 2 & 10 & - & - \\
\hline 3 & 05.50 menit & 1 & 5 & - & - \\
\hline 4 & 05.10 menit & 1 & 5 & - & - \\
\hline 5 & 04.55 menit & 1 & 5 & - & - \\
\hline 6 & 04.50 menit & 1 & 5 & - & - \\
\hline 7 & 04.30 menit & 1 & 5 & - & - \\
\hline 8 & 04.18 menit & 1 & 5 & - & - \\
\hline 9 & 04.10 menit & 1 & 5 & - & - \\
\hline 10 & 03.40 menit & 2 & 10 & - & - \\
\hline 11 & 03.30 menit & 1 & 5 & - & - \\
\hline 12 & 03.22 menit & 1 & 5 & - & - \\
\hline 13 & 03.20 menit & 1 & 5 & - & - \\
\hline 14 & 03.07 menit & 1 & 5 & - & - \\
\hline 15 & 03.00 menit & 1 & 5 & - & - \\
\hline 16 & 02.36 menit & 1 & 5 & - & - \\
\hline 17 & 02.19 menit & 2 & 10 & - & - \\
\hline 18 & 30 hari & - & - & 20 & 100 \\
\hline \multirow{2}{*}{\multicolumn{2}{|c|}{$\begin{array}{l}\text { Jumlah } \\
\text { Waktu Rata-rata }\end{array}$}} & 20 & 100 & 20 & 100 \\
\hline & & 04.1 & & \multicolumn{2}{|c|}{30 hari } \\
\hline
\end{tabular}

Berdasar data pada tabel 1 rata-rata lamanya waktu pelaporan pada kelompok intervensi adalah 04.19 menit sementara pada kelompok kontrol rata-rata lama waktu pelaporan pemeriksaan fisik nifas adalah 30 hari. Sehingga dapat disimpulkan bahwa pelaporan hasil pemeriksaan masa nifas dengan menggunakan sistem informasi lebih cepat jika dibandingkan dengan manual menggunakan standar pelayanan kemenkes. 


\section{Perbedaan Rerata Kecepatan Pelaporan Berbasis Sistem dengan Pemeriksaan Manual Sesuai Standar Pelayanan Kemenkes.}

Perbedaan rerata kecepatan pelaporan berbasis sistem dengan pemeriksaan manual sesuai standar pelayanan kemenkes dapat dilihat pada tabel 2:

Tabel 2

Perbedaan Kecepatan Pelaporan Berbasis Sistem Informasi dengan Pemeriksaan Manual Sesuai Standar Pelayanan Kemenkes

\begin{tabular}{lccccc}
\hline \multicolumn{1}{c}{ Kelompok } & $\mathrm{N}$ & Mean & $S D$ & Mean Rank & p-value \\
\cline { 1 - 5 } $\begin{array}{l}\text { Intervensi (Sistem } \\
\text { Informasi) }\end{array}$ & 20 & 10.10 & 5.241 & 30.50 & \multirow{2}{*}{0.000} \\
\cline { 1 - 5 } Kontrol (Manual) & 20 & 1.000 & 0.000 & 10.50 & \\
\hline
\end{tabular}

Berdasar data pada tabel 1.2 menunjukkan hasil uji statistik mean pada kelompok intervensi (sistem informasi) sebesar 10.10 dengan standar deviasi 5.241 dan nilai mean pada kelompok kontrol sebesar 1.000 dengan standar deviasi 0.000. Mean rank pada kelompok intervensi (sistem informasi) sebesar 30.50 dan pada kelompok kontrol sebesar 10.50. Berdasarkan intepretasi data dapat ditarik kesimpulan bahwa pada kecepatan pelaporan kelompok intervensi lebih cepat jika dibandingkan dengan kelompok kontrol menggunakan manual standar pelayanan Kemenkes, hal ini dapat dilihat dari nilai mean, standar deviasi serta mean rank dari kelompok intervensi yang lebih tinggi jika dinadingkan dengan kelompok kontrol. Hasil uji statistik dengan menggunakan Mann Whithney di dapatkan nilai $p$-vallue sebesar $0.000<0.05(\alpha)$ sehingga Ha diterima dan Ho ditolak atau dengan kata lain ada perbedaan waktu pemberian pelayanan rekomendasi sistem informasi rule based system pada ibu postpartum.

\section{PEMBAHASAN}

Hasil uji statistik menyatakan bahwa terdapat perbedaan yang bermakna pada kecepatan sistem pelaporan antara kelompok intervensi menggunakan sistem informasi dan kelompok kontrol menggunakan manual standar pelayanan Kemenkes $p$-value adalah 0.000 ( $p<0.05)$. Mean rank pada kelompok intervensi (sistem informasi) sebesar 30.50 dan pada kelompok kontrol sebesar 10.50. Dari hasil uji hipotesa penelitian menunjukkan bahwa kecepatan pelaporan pada kelompok intervensi lebih cepat jika dibandingkan dengan kelompok kontrol.

Hal ini juga dapat dilihat pada tabel 1 rata-rata lamanya waktu pelaporan pada kelompok intervensi adalah 04.19 menit sementara pada kelompok kontrol rata-rata lama waktu pelaporan pemeriksaan fisik nifas adalah 30 hari. Sehingga dapat disimpilkan bahwa pelaporan hasil pemeriksaan masa nifas dengan menggunakan sistem informasi lebih cepat jika dibandingkan dengan manual menggunakan standar pelayanan kemenkes.

Hasil penelitian ini sesuai dengan penelitian yang dilakukan oleh Bakibinga et all pada tahun 2017 Aplikasi mPAMANECH (mobile Partnership for Maternal, Neonatal dan Children Health) menggunakan ponsel dan portal web untuk membantu CHV membuat keputusan dalam memberikan layanan pada ibu dan bayi. Data diperoleh melalui metode kualitatif dan kuantitatif Inovasi mHealth (mPAMANECH) dapat meningkatkan kesehatan ibu, bayi dan anak. Sistem ini mempercepat sistem pelaporan 
hasil pemeriksaan dan dapat diadopsi oleh pemerintah daerah maupun pusat untuk menutupi keterbatasan sumber daya yang ada (Bakibinga et al., 2017).

Hasil penelitian ini sejalan dengan hasil penelitian Padila, dkk (2018), dimana sistem informasi manajemennya berbasis web dengan menggunakan alat bantu computer/laptop sebagai sarana teknologi informasi sehingga mampu menyediakan serta mensupport pasien dan perawat untuk saling memberikan informasi yang lebih efektif tanpa memikirkan jarak yang menjadi penghalang. Selain itu Teknologi ini juga memungkinkan tenaga kesehatan dan keperawatan profesional untuk tetap bisa memantau dari jarak jauh segala kondisi dan situasi pasien selama di rumah, khususnya kondisi yang mengarah pada keadaan abnormal. Untuk selanjutnya bisa menjadi pertimbangan untuk menentukan tindakan keperawatan dan kesehatan yang dibutuhkan oleh pasien apakah pasien tetap dirawat dirumah atau pasien harus dirujuk ke RS (Padila, P., Lina, L., Febriawati, H., Agustina, B., \& Yanuarti, R. (2018).

Penelitian lain yang dilakukan oleh Fajria pada tahun 2016 yang menyatakan bahwa penggunaan sistem informasi pada deteksi dini kehamilan resiko tinggi memiliki waktu yang lebih cepat dibandingkan dengan sistem manual dalam segi pelaporan yang dilakukan (Fajriya, 2017). Senada dengan hal tersebut, penelitian yang dilakukan di Kenya pada tahun 2015 oleh Warren et all mengungkapkan bahwa dengan adanya pengembangan sistem informasi guna mendukung pengambilan keputusan klinis waktu yang dibutuhkan oleh tenaga kesehatan dan tenaga sukarelawan lebih cepat. Kecepatan dalam pelaporan hasil pemeriksaan kepada klien akan mempengaruhi kualitas dari tempat pelayanan kesehatan tersebut. Kecepatan pelaporan hasil pemeriksaan akan berdampak pada perubahan pengambilan keputusan yang lebih cepat (Warren et al., 2015).

Sistem informasi merupakan satu solusi dari permasalahan yang ada mengenai kecepatan sistem pelaporan yang dilakukan oleh tenaga kesehatan. Dengan adanya bantuan dari sistem informasi maka pelaporan kesehatan yang dilakukan akan jauh lebih cepat dan lebih murah karena akan menghemat banyak biaya transportasi jika pelaporan harus dilakukan secara manual. Dengan bantuan sistem informasi maka data yang berada di daerah pedesaan serta pedalaman dapat dilaporkan jauh lebih cepat jika dibandingkan dengan pelaporan manual yang dapat meringankan kerja tenaga kesehatan. Pelaporan yang lebih cepat akan membuat pemangku kebijakan lebih cepat bertindak dalam mengambil keputusan guna mengeluarkan kebijakan yang dapat digunakan untuk mengatasi permasalahan kesehatan yang ada baik di desa maupun di kota (Agarwal et al., 2016, Barrote et al., 2014, Bert et al., 2014, Craswell et al., 2013, Labrique et al., 2013).

\section{SIMPULAN}

Pelayanan nifas menggunakan sistem informasi secara otomatis akan memberikan data laporan hasil pemeriksaan, rekap data secara lengkap yang berisi identitas pasien, identitas bidan/tenaga kesehatan pemeriksa dan hasil pemeriksaan oleh bidan atau tenaga kesehatan lebih cepat menjadi 4.19 menit jika dibandingkan dengan manual sesuai standar pelayanan dari kemenkes. Hal ini terbukti dengan $p$-vallue sebesar 0.000 $(<0.05)$ sehingga dapat disimpulkan terdapat perbedaan kecepatan pelaporan pelayanan nifas menggunakan sistem informasi dibandingkan dengan manual sesuai standar pelayanan dari kemenkes. 


\section{SARAN}

Sistem informasi pelayanan nifas berbasis web memerlukan stabilitas teknis karena akses informasi yang terdapat dalam SIM dilakukan secara online sehingga membutuhkan koneksi internet dan dalam operasional pelaporan harus memenuhi standar pelayanan kesehatan yang disesuaikan dengan kebutuhan pasien.

\section{DAFTAR PUSTAKA}

Agarwal, S., Lefevre, A. E., Lee, J., L’engle, K., Mehl, G., Sinha, C. \& Labrique, A. (2016). "Guidelines for Reporting of Health Interventions Using Mobile Phones: Mobile Health (mHealth) Evidence Reporting and Assessment (mERA) Checklist". Bmj, 352, i1174

Bakibinga, P., Kamande, E., Omuya, M., Ziraba, A. K. \& Kyobutungi, C. (2017). "The Role of a Decision-Support Smartphone Application in Enhancing Community Health Volunteers' Effectiveness to Improve Maternal and Newborn Outcomes in Nairobi, Kenya: Quasi-Experimental Research Protocol". BMJ open, 7, e014896

Barrote, A., Silva, P., Gonçalves, F. \& Cruz-Correia, R. (2014). "Obstetric Information System: Effectiveness in Health Care Practice". Procedia Technology, 16, 14111416

Bert, F., Giacometti, M., Gualano, M. R. \& Siliquini, R. (2014). "Smartphones and Health Promotion: A Review of the Evidence". Journal of medical systems, 38, 9995.

Cheng, S., Chen, W., Yang, Y., Chu, P., Liu, X., Zhao, M., Tan, W., Xu, L., Wu, Q., Guan, H., Liu, J., Liu, H., Chen, R. Y. \& Jia, Z. (2013). "Effect of Diagnostic and Treatment Delay on the Risk of Tuberculosis Transmission in Shenzhen, China: An Observational Cohort Study, 1993-2010". Plos One, 8, e67516.

Craswell, A., Moxham, L. \& Broadbent, M. (2013). "Perinatal Data Collection: Current Practice in the Australian Nursing and Midwifery Healthcare Context". Health Information Management Journal, 42, 11-17.

Dinas Kesehatan Kota Semarang. (2016). Profil Kesehatan Kota semarang Tahun 2016 [Online].

Available: http://dinkes.semarangkota.go.id/?p=halaman_mod\&jenis=profil\#.

Dinas Kesehatan Provinsi Jawa Tengah. (2016). Profil Kesehatan Provinsi Jawa Tengah Tahun 2016 [Online]. Available: http://www.dinkesjatengprov.go.id/v2015/dokumen/profil2016/mobile/index.html $\# \mathrm{p}=30$.

Fajriya, I. I. (2017). Deteksi Kehamilan Resiko Tinggi dengan Sistem Informasi Berbasis Web. unpublished, Poltekkes Kemenkes Semarang

Graham, W., Woodd, S., Byass, P., Filippi, V., Gon, G., Virgo, S., Chou, D., Hounton, S., Lozano, R., Pattinson, R. \& Singh, S. (2016). "Diversity and Divergence: the Dynamic Burden of Poor Maternal Health". The Lancet, 388, 2164-2175

Kementrian Kesehatan Republik Indonesia. (2016). Profil Kesehatan Indonesia Tahun 2016 [Online]. Available: www.pusdatin.kemkes.go.id/.../profilkesehatan.../Profil-Kesehatan-Indonesia-2016.pdf

Koblinsky, M., Moyer, C. A., Calvert, C., Campbell, J., Campbell, O. M. R., Feigl, A. B., Graham, W. J., Hatt, L., Hodgins, S., Matthews, Z., Mcdougall, L., Moran, A. C., Nandakumar, A. K. \& Langer, A. (2016). "Quality Maternity Care for Every Woman, Everywhere: a Call to Action". The Lancet, 388, 2307-2320 
Kristensen, K. L., Podlekareva, D. \& Ravn, P. (2017). "Delayed Diagnosis of Severe Tuberculous Spondylodiscitis in an Asylum Seeker; Patient or Doctors Delay?". Respiratory Medicine Case Reports, 21, 145-146

Labrique, A. B., Vasudevan, L., Kochi, E., Fabricant, R. \& Mehl, G. (2013). "mHealth Innovations as Health System Strengthening Tools: 12 Common Applications and a Visual Framework". Global Health: Science and Practice, 1, 160-171

Miah, S. J., Gammack, J. \& Hasan, N. (2017). "Extending the Framework for Mobile Health Information Systems Research: A Content Analysis". Information Systems.

Minghella, E., Lakhani, M., Hughes, C. \& Thomas., B. (2010). Delayed Diagnosis of Cancer: Thematic Review Presents the Findings Of A Project at The NPSA Which was Designed to Explore Issues of Patient Safety Around Delayed Diagnosis of Cancer, and Provide the NHS with Potential Solutions. [Online]. National Patient Safety Agency. Available: http:// www. nrls. npsa. nhs. uk/ resources /?entryid45 $=69894$.

Padila, P., Lina, L., Febriawati, H., Agustina, B., \& Yanuarti, R. (2018). Home Visit Berbasis Sistem Informasi Manajemen Telenursing. Jurnal Keperawatan Silampari, 2(1), 217-235. https://doi.org/https://doi.org/10.31539/jks.v2i1.305

Renfrew, M. J., Mcfadden, A., Bastos, M. H., Campbell, J., Channon, A. A., Cheung, N. F., Silva, D. R. a. D., Downe, S., Kennedy, H. P. \& Malata, A. (2014). "Midwifery and Quality Care: Findings from a New Evidence-Informed Framework for Maternal and Newborn Care". The Lancet, 384, 1129-1145

Shiferaw, S., Spigt, M., Tekie, M., Abdullah, M., Fantahun, M. \& Dinant, G.-J. (2016). "The Effects of a Locally Developed mHealth Intervention on Delivery and Postnatal Care Utilization; A Prospective Controlled Evaluation among Health Centres in Ethiopia". PloS one, 11, e0158600

Trayner, I. \& Taylor, L. (2017). "NHS Western Isles-Involving Our Patients: Faster Access to Treatment for Hypertension in Primary Care". International Journal of Integrated Care, 17

Warren, C. E., Abuya, T., Kanya, L., Obare, F., Njuki, R., Temmerman, M. \& Bellows, B. (2015). "A Cross Sectional Comparison of Postnatal Care Quality in Facilities Participating in a Maternal Health Voucher Program Versus Non-Voucher Facilities in Kenya". BMC pregnancy and childbirth, 15, 153 